\title{
Maternal and Neonatal Outcomes Resulting from Antepartum Hemorrhage in Women with Placenta Previa and Its Associated Risk Factors: A Single-Center Retrospective Study
}

This article was published in the following Dove Press journal:

Therapeutics and Clinical Risk Management

\author{
Shu-Yu Long \\ Qiong Yang \\ Rui Chi \\ Li Luo (D) \\ Xi Xiong \\ Zheng-Qiong Chen
}

Department of Obstetrics and Gynecology, The Second Affiliated Hospital of Army Medical University, Chongqing 400037, People's Republic of China
Correspondence: Zheng-Qiong Chen Email chenzhengqiong75@163.com

\begin{abstract}
Purpose: Antepartum hemorrhage (APH) in women with placenta previa (PP) has been associated with increased perinatal complications. The present study aims to evaluate the maternal and neonatal outcomes, and risk factors related to this condition.

Methods: This retrospective study was conducted in the Obstetrics and Gynecology Department of the Second Affiliated Hospital of Army Military Medical University from January 2016 to September 2019, which included all women with PP. The clinical and ultrasound features in patients with or without APH were compared.

Results: There were 233 women with APH and 302 women without APH in the cohort. Most of the women with APH were prone to adverse maternal and neonatal outcomes. In the logistic regression analysis, cervical length was inversely correlated to APH (OR: 0.972, 95\% CI: 0.952 0.993), while complete PP increased the risk for APH (OR: $2.121,95 \% \mathrm{CI}$ : 1.208 3.732). Furthermore, the anterior placenta increased the risk for APH (OR: 1.664, 95\% CI: 1.139 2.430), the partial absence of the over lying myometrium increased the risk for APH (OR: 2.015, 95\% CI: 1.293 3.141), and the previous history of uterine artery embolization (UAE) increased the highest risk for APH (OR: 11.706, 95\% CI: 1.424 96.195).

Conclusion: Obstetricians should be aware of the increased risk of adverse pregnancy outcomes related to APH in women with complete PP, short cervical length, anterior placenta, and partially absent over lying myometrium. Prior UAE is a novel risk factor associated with increased prevalence of APH.
\end{abstract}

Keywords: placenta previa, antepartum hemorrhage, bleeding, pregnancy complications, risk factor

\section{Introduction}

Antepartum hemorrhage (APH), which is defined as vaginal bleeding events occurring during the second half of pregnancy (after 20 weeks of estimated gestational age until delivery), remains as an important cause of perinatal mortality and maternal morbidity worldwide. ${ }^{1}$ In addition to maternal morbidity secondary to acute hemorrhage and operative delivery, the fetus may be compromised by uteroplacental insufficiency, premature birth and perinatal death. ${ }^{2}$ The chief cause of serious vaginal bleeding in late-term pregnancy is placenta previa (PP), which occurs when the placenta implants in a location overlies or abuts the internal 
cervical os. ${ }^{3}$ The overall prevalence of PP has been estimated to be approximately five per 1000 pregnancies by world region, and this has been increasing with the increased utilization of cesarean section, and the growing number of women who have been postponing maternity worldwide. ${ }^{4}$ Other risk factors associated with PP include chronic hypertension, multiparity, multiple gestations, tobacco use, uterine curettage, inadequate prenatal care, and male fetal gender. ${ }^{5,6}$

Studies have suggested that pregnant women with PP experience higher rates of $\mathrm{APH}$, when compared to the general population of women. ${ }^{7}$ It was reported that the prevalence of APH in pregnant women with PP is approximately 10 times greater, when compared to non-PP women. ${ }^{8}$ The reported rate of APH in women with PP varied across studies, which ranged within $20-90 \%$, and this was associated with the high rates of perinatal complications, such as preterm cesarean delivery and cesarean hysterectomy. ${ }^{9,10}$ Although APH is common in pregnant women with PP, this has not been extensively studied. Furthermore, the management of PP and timing of delivery are influenced by gestational age and fetal lung maturity, which are balanced against the degree of hemorrhage and urgency of the maternal condition. ${ }^{11}$ Hence, a question correlated to PP patients arises: who are more likely to have APH, and who should be timely admitted for scheduled delivery? Importantly, the APH relevant pregnancy outcomes and individual factors for predicting PP with APH remain uncertain.

Thus, a reliable prevalence estimate of APH in PP is important in informing efforts to identify high-risk patients, and in the prevention and management among pregnant women with PP, which would perhaps provide directions for future studies and relevant public health strategies. The present study aims to elucidate and assess the maternal and neonatal outcomes and risk factors correlated to PP with APH in our large database.

\section{Patients and Methods}

The present retrospective study included pregnant women with PP who delivered after 28 weeks at the Obstetrics and Gynecology Department of the Second Affiliated Hospital of Army Military Medical University, between January 2016 and September 2019. Our center is a tertiary medical center that has a computerized database of all deliveries. Medical records pertaining to the demographic characteristics, medical and obstetrical history, and present pregnancy, as well as the delivery, puerperal and neonatal outcomes, were all carefully obtained from the computerized database. The present study was reviewed and approved by the Legitimate Review Board of Army Medical University of China (protocol number 2020-129-01).

The PP diagnosis was based on the transabdominal and transvaginal ultrasound performed at admission, and was confirmed during the caesarean section. The APH is defined as vaginal bleeding events occurring and the total antepartum blood loss $\geq 20 \mathrm{~mL}$ during the second half of pregnancy until delivery. Women with fetal malformation or had missing antenatal/outcome variables or who had vaginal bleeding but a total antepartum blood loss $<20 \mathrm{~mL}$ were excluded from the study. The latter was excluded because little blood loss can hardly differentiate with bloody show, which is commonly accompanied by bloodtinged mucus or a small amount of blood. These patients were divided into two groups, and were compared: (1) patients with PP with APH (study group); (2) patients with PP without APH (control group). The ultrasound features for each woman was recorded. Sonographic examinations were performed using the GE VOLUSON E8 imaging machine (General Electric Co., USA) or the Philips IU-Elite system (Philips Electronics NV, Netherlands) with a 4-9-MHz transvaginal transducer by two skilled obstetric ultrasound technicians.

\section{Clinical Definitions}

Type of placenta previa (marginal PP when the lower placental edge abuts the internal cervical os, but does not cover it, partial PP when the lower placental edge partially covers the internal os, and complete PP when the internal os is completely covered by the placenta). The type of placenta accrete was made according to the classification diagnosis referred to the FIGO clinical and histopathological classification, which include abnormally adherent placenta (placenta adherenta or creta), abnormally invasive placenta (Increta), and abnormally invasive placenta (Percreta). ${ }^{12}$ The other special ultrasound features, such as partially absent over lying myometrium, loss of the retroplacental clear zone, number of placental lacunae, utero-vesical hypervascularity doppler signal grading, and antepartum cervical length, were described, according to previous studies. ${ }^{13-15}$

The following maternal and neonatal data were retrospectively collected from medical records: maternal age, number of pregnancies/parity/artificial abortions/cesarean deliveries, type of placenta previa, type of placenta 
accrete, placental location, special ultrasound features, previous history of $\mathrm{PP} /$ postpartum hemorrhage $(\mathrm{PPH})$ cesarean scar pregnancy (CSP)/blood transfusion/uterine artery embolization (UAE)/uterine surgeries (myomectomy, septum resection, or hysteroscopic treatment of intrauterine adhesion), use of tocolytics, type of cesarean section, estimated intraoperative blood loss, intraoperative blood transfusing, peripartum hysterectomy, bladder injury, salvage therapy with UAE, mean operation time, duration of hospitalization, expenses, need for rehospitalization, puerperal infection, wound infection, gestational age at delivery, preterm delivery, birth weight, apgar score, neonatal complications, and admission to the Neonatal Intensive Care Unit (NICU).

\section{Statistical Analysis}

The data on continuous variables with a normal distribution was presented as mean $\pm \mathrm{SD}$, and compared between study groups using Student's $t$-test. Continuous variables not normally distributed and ordinal variables were presented in median with the inter-quartile range (IQ range), and the statistical analysis was performed using the Mann-Whitney test. The categorical data was presented in counts and percentages, and the differences were assessed by Pearson ChiSquare or Continuity Correction, when appropriate. The binary logistic regression with forward stepwise (wald) method was used to determine the independent risk factors for PP with APH. $P<0.05$ was considered statistically significant. The statistical analysis was performed using the SPSS package 20th edition (SPSS Inc., Chicago, IL, USA).

\section{Results}

There were a total of 18,071 deliveries from our hospital over the 4-year study period and a total sample size of 535 women with PP was obtained. As a complication at the second half of pregnancy, APH occurred in $43.6 \%$ of PP pregnancies $(\mathrm{n}=233)$. Among these patients, 12 patients (2.2\%) had APH with blood loss of $\geq 500 \mathrm{~mL}$ and five patients $(0.9 \%)$ had severe APH with blood loss of $\geq 1000 \mathrm{~mL}$. In addition, there were seven cases $(1.3 \%)$ of peripartum hysterectomy, one case $(0.2 \%)$ of bladder injury, 37 cases $(6.9 \%)$ of salvage therapy with UAE, five cases $(0.9 \%)$ of re-hospitalization, 11 cases $(2.1 \%)$ of puerperal infection, and no cases of maternal death.

The demographics characteristics and ultrasound features between these groups of PP, with or without APH, are presented in Table 1. The median maternal age (IQ range) was 31.0 (28.0-34.9) years old for women with
APH and 31.6 (28.9-35.0) years old for women without APH. The difference was not statistically significant. The univariate analysis revealed that women with APH were more likely to have more pregnancies, greater parity, and more previous CSs, when compared with women without APH. A significantly higher proportion of women were complete PP $(78.5 \%$ vs $64.2 \%$; $\mathrm{P}=0.001)$, placenta percreta $(18.5 \%$ vs $9.9 \% ; \mathrm{P}=0.001)$, and anterior placental (54.1\% vs $37.1 \% ; \mathrm{P}=0.001$ ), among the women with APH. Special ultrasound features, such as partially absent over lying myometrium, loss of the retroplacental clear zone, number of placental lacunae, utero-vesical hypervascularity Doppler signal grading, antepartum cervical length and previous history of UAE, were all significantly associated with APH $(\mathrm{P}<0.05)$. However, there was no association with maternal age, number of artificial abortions, previous history of $\mathrm{PP} / \mathrm{PPH} / \mathrm{CSP} /$ blood transfusion, or previous history of uterine surgeries.

The maternal and neonatal outcomes of PP with and without APH are presented in Table 2. The proportion of women that used tocolytics ( $72.5 \%$ vs $16.2 \%)$, emergency CS $(38.2 \%$ vs $7.6 \%)$, peripartum hysterectomy $(3.0 \%$ vs $0.0 \%)$, salvage therapy with UAE $(9.9 \%$ vs $4.6 \%)$, and puerperal infection (3.9\% vs $0.7 \%$ ) were significantly higher for women with APH, when compared to those without APH. Women with APH had more estimate intraoperative blood loss, more blood transfusing, longer mean operation time, higher expenses and longer average hospitalization days, and these were significant, when compared to women who did not have APH. The perinatal outcomes of gestational age at delivery, preterm delivery, birth weight, Apgar score, neonatal complications and admission to NICU were all significant between the study group and control group $(\mathrm{P}<0.05)$. However, there was no association with bladder injury, need for re-hospitalization, or wound infection.

A binary logistic regression model was constructed to determine the independent risk factors for PP with APH (Table 3). The model revealed that type of placenta, antepartum cervical length, placental location, partially absent over lying myometrium, and previous history of UAE remained as the significant factors associated with APH, while other parameters, such as number of pregnancies, parity, number of cesarean deliveries, type of placenta accrete, loss of the retroplacental clear zone, number of placental lacunae, and utero-vesical hypervascularity Doppler signal grading were excluded. Cervical length was inversely correlated to APH (OR: $0.972,95 \% \mathrm{CI}$ : 0.952 0.993), while complete PP increased the risk for 
Table I Demographic Characteristics and Ultrasound Features

\begin{tabular}{|c|c|c|c|}
\hline Variables & PP with APH $(n=233)$ & PP without APH $(n=302)$ & P-value \\
\hline Maternal age ${ }^{a}$ & $31.0(28.0-34.9)$ & $31.6(28.9-35.0)$ & 0.270 \\
\hline Number of pregnancies ${ }^{\mathrm{a}}$ & $4.0(3.0-5.0)$ & $4.0(2.8-5.0)$ & 0.024 \\
\hline Parity $^{\mathrm{a}}$ & $1.0(1.0-2.0)$ & $1.0(1.0-2.0)$ & 0.001 \\
\hline Number of artificial abortions ${ }^{a}$ & $2.0(1.0-3.0)$ & $2.0(1.0-2.0)$ & 0.172 \\
\hline Number of cesarean deliveries ${ }^{b}$ & & & 0.011 \\
\hline 0 & $97.0(41.6)$ & I $40.0(46.4)$ & \\
\hline I & $108.0(46.4)$ & $147.0(48.7)$ & \\
\hline$\geq 2$ & $28.0(12.0)$ & $15.0(5.0)$ & \\
\hline Type of placenta previa ${ }^{\mathrm{b}}$ & & & 0.001 \\
\hline Marginal PP & $21.0(9.0)$ & $58.0(19.2)$ & \\
\hline Partial PP & $29.0(12.4)$ & $50.0(16.6)$ & \\
\hline Complete PP & $183.0(78.5)$ & $194.0(64.2)$ & \\
\hline Type of placenta accrete ${ }^{b}$ & & & 0.001 \\
\hline No placenta accreta & $88.0(37.8)$ & $|7| .0(56.6)$ & \\
\hline Placenta adherenta & $54.0(23.2)$ & $58.0(19.2)$ & \\
\hline Placenta increta & $48.0(20.6)$ & $43.0(14.2)$ & \\
\hline Placenta percreta & $43.0(18.5)$ & $30.0(9.9)$ & \\
\hline Placental location ${ }^{\mathrm{b}}$ & & & 0.001 \\
\hline Anterior & $126.0(54.1)$ & 112.0 & \\
\hline Posterior & $97.0(41.6)$ & $172.0(57.0)$ & \\
\hline Others & $10.0(4.3)$ & $18.0(6.0)$ & \\
\hline Partially absent of the over lying myometrium ${ }^{b}$ & $82.0(35.2)$ & $47.0(15.6)$ & 0.001 \\
\hline Loss of the retroplacental clear zone ${ }^{b}$ & $83.0(35.6)$ & $50.0(16.6)$ & 0.001 \\
\hline Number of placental lacunae ${ }^{b}$ & & & 0.001 \\
\hline 0 & $145.0(62.2)$ & $239.0(79.1)$ & \\
\hline I & $25.0(10.7)$ & $16.0(5.3)$ & \\
\hline$\geq 2$ & $63.0(27.0)$ & $47.0(15.6)$ & \\
\hline Utero-vesical hypervascularity doppler signal grading ${ }^{\mathrm{b}}$ & & & 0.001 \\
\hline I & $19.0(8.2)$ & I5.0 (5.0) & \\
\hline II & $42.0(18.0)$ & $34.0(11.3)$ & \\
\hline III & $37.0(15.9)$ & $21.0(7.0)$ & \\
\hline Antepartum cervical length $(\mathrm{mm})^{\mathrm{a}}$ & $31.0(25.6-38.0)$ & $35.0(29.6-40.0)$ & 0.001 \\
\hline Previous history of PPc & $7.0(3.0)$ & $4.0(1.3)$ & 0.294 \\
\hline Previous history of $\mathrm{CSP}^{\mathrm{C}}$ & $7.0(3.0)$ & $2.0(0.7)$ & 0.080 \\
\hline Previous history of $\mathrm{PPH}^{\mathrm{c}}$ & $4.0(1.7)$ & $2.0(0.7)$ & 0.463 \\
\hline Previous history of blood transfusion ${ }^{\mathrm{b}}$ & $7.0(3.0)$ & $5.0(1.7)$ & 0.296 \\
\hline Previous history of $\mathrm{UAE}^{\mathrm{c}}$ & $10.0(4.3)$ & $\mathrm{I} .0(0.3)$ & 0.004 \\
\hline History of uterine surgeries ${ }^{b}$ & $8.0(3.4)$ & $8.0(2.6)$ & 0.597 \\
\hline
\end{tabular}

Notes: ${ }^{a}$ Mann-Whitney test; ${ }^{b}$ Pearson Chi-square test; ${ }^{c}$ Continuity Correction; Values are given as mean \pm SD, number (percentage), or median (inter-quartile range). Abbreviations: CSP, cesarean scar pregnancy; PPH, postpartum hemorrhage; UAE, uterine artery embolization.

APH (OR: 2.121, 95\% CI: 1.208 3.732), anterior placenta increased the risk for APH (OR: 1.664, 95\% CI: 1.139 2.430), partially absent over lying myometrium increased the risk for APH (OR: 2.015, 95\% CI: 1.293 3.141), and previous history of UAE increased the highest risk for APH (OR: 11.706, 95\% CI: 1.424 96.195). However, there was no risk association with partial PP vs marginal PP (OR: 1.606, 95\% CI: $0.798 \sim 3.234)$ and others placenta vs posterior placenta (OR 0.916, 95\% CI 0.398 2.108). 
Table 2 Pregnancy Outcomes

\begin{tabular}{|c|c|c|c|}
\hline Variables & PP with APH $(n=233)$ & PP without APH $(n=302)$ & $P$-value \\
\hline Use of tocolytics ${ }^{b}$ & $169.0(72.5)$ & $49.0(16.2)$ & 0.001 \\
\hline The type of cesarean section ${ }^{b}$ & & & 0.001 \\
\hline Elective CS & $144.0(6 \mid .8)$ & $279.0(92.4)$ & \\
\hline Emergency CS & $89.0(38.2)$ & $23.0(7.6)$ & \\
\hline Estimate intraoperative blood loss $(\mathrm{mL})^{\mathrm{a}}$ & $800.0(600.0-1200.0)$ & $800.0(500.0-1000.0)$ & 0.001 \\
\hline Intraoperative blood transfusing $(\mathrm{mL})^{\mathrm{a}}$ & $400.0(0.0-600.0)$ & $0.0(0.0-400.0)$ & 0.001 \\
\hline Peripartum hysterectomy ${ }^{c}$ & $7.0(3.0)$ & $0.0(0.0)$ & 0.008 \\
\hline Bladder injury ${ }^{c}$ & $1.0(0.4)$ & $0.0(0.0)$ & 0.896 \\
\hline Salvage therapy with $U A E^{b}$ & $23.0(9.9)$ & $14.0(4.6)$ & 0.018 \\
\hline Mean operation time $(\mathrm{min})^{\mathrm{a}}$ & $105.0(80.0-145.0)$ & $95.0(75.0-120.0)$ & 0.004 \\
\hline Duration of hospitalization (day) ${ }^{\mathrm{a}}$ & $6.0(4.0-8.0)$ & $4.0(4.0-5.0)$ & 0.001 \\
\hline Expenses (yuan) ${ }^{\mathrm{a}}$ & $26,991.0(22,289.0-32,965.0)$ & $22,765.0(19,241.0-27,002.0)$ & 0.001 \\
\hline Need for re-hospitalization ${ }^{c}$ & $4.0(1.7)$ & $1.0(0.3)$ & 0.231 \\
\hline Puerperal infection ${ }^{c}$ & $9.0(3.9)$ & $2.0(0.7)$ & 0.023 \\
\hline Wound infection ${ }^{c}$ & $3.0(1.3)$ & $3.0(1)$ & I \\
\hline Gestational age at delivery ${ }^{\mathrm{a}}$ & $35.1(33.6-36.2)$ & $37.2(36.3-38.1)$ & 0.001 \\
\hline Preterm delivery ${ }^{\mathrm{b}}$ & $200.0(85.8)$ & $110.0(36.4)$ & 0.001 \\
\hline Birth weight $(g)^{d}$ & $2500.6 \pm 499.4$ & $2970.8 \pm 435.2$ & 0.001 \\
\hline Apgar score at I $\min ^{\mathrm{a}}$ & $10.0(9.0-10.0)$ & $10.0(10.0-10.0)$ & 0.001 \\
\hline Apgar score at $5 \min ^{\mathrm{a}}$ & $10.0(9.0-10.0)$ & $10.0(10.0-10.0)$ & 0.001 \\
\hline Apgar score at $10 \mathrm{~min}^{\mathrm{a}}$ & $10.0(9.0-10.0)$ & $10.0(10.0-10.0)$ & 0.001 \\
\hline Toal apgar score ${ }^{a}$ & $30.0(27.0-30.0)$ & $30.0(27.0-30.0)$ & 0.001 \\
\hline Neonatal complications $^{c}$ & II $5.0(49.4)$ & $36.0(11.9)$ & 0.001 \\
\hline Admission to $\mathrm{NICU}^{\mathrm{b}}$ & $118.0(50.6)$ & $36.0(11.9)$ & 0.001 \\
\hline
\end{tabular}

Notes: ${ }^{\mathrm{a} M a n n-W h i t n e y ~ t e s t ; ~}{ }^{\mathrm{b}}$ Pearson Chi-square test; 'Continuity Correction; ${ }^{\mathrm{d} S}$ Student's $t$-test. Values are given as mean $\pm \mathrm{SD}$, number (percentage), or median (interquartile range).

Abbreviations: CS, cesarean section; UAE, uterine artery embolization; NICU, neonatal intensive care unit.

Based on the above model, with the presence of either one of the five significant factors being categorized as positive for high risk of APH, the overall prediction rate was $65.6 \%$, and the sensibility, specificity, positive predictive value and negative predictive value was $44.6 \%$, $81.8 \%, 65.7 \%$ and $34.6 \%$, respectively.

\section{Discussion}

PP with APH is a relatively common clinical scenario worldwide. A systematic review and meta-analysis pooled the overall prevalence of APH among pregnant women with PP, which was 51.6\% (95\% CI: 42.7-60.6), in a heterogeneous set of studies. ${ }^{16}$ Our results were similar, showed an incidence of PP with APH in our tertiary centers was $43.6 \%$. Furthermore, PP pregnancies with APH have been shown to be mostly prone to adverse maternal and neonatal outcomes. Higher incidence of emergency CS, hysterectomy, hemorrhage associated complications and puerperal infection were found in the APH group. Meanwhile, earlier gestational ages, higher probability of preterm delivery, neonatal complications and admission to the NICU, lower birth weight, and Apgar 
Table 3 Logistic Regression for the Indicators for APH

\begin{tabular}{|c|c|c|c|c|}
\hline Variables & B & Wald & $P$ & OR (95\%CL) \\
\hline \multicolumn{5}{|l|}{ Type of placenta } \\
\hline Partial PP vs marginal PP & 0.474 & 1.760 & 0.185 & $1.606(0.798 \sim 3.234)$ \\
\hline Complete PP vs marginal PP & 0.752 & 6.853 & 0.009 & 2.121 ( $1.208 \sim 3.732)$ \\
\hline Antepartum cervical length $(\mathrm{mm})$ & -0.028 & 6.614 & 0.010 & $0.972(0.952 \sim 0.993)$ \\
\hline \multicolumn{5}{|l|}{ Placental location } \\
\hline Anterior vs posterior & 0.509 & 6.929 & 0.008 & $1.664(1.139 \sim 2.430)$ \\
\hline Others vs posterior & -0.088 & 0.042 & 0.836 & $0.916(0.398 \sim 2.108)$ \\
\hline Partially absent of the over lying myometrium & 0.701 & 9.578 & 0.002 & $2.015(1.293 \sim 3.14 \mathrm{I})$ \\
\hline Previous history of UAE & 2.460 & 5.240 & 0.022 & $11.706(1.424 \sim 96.195)$ \\
\hline
\end{tabular}

Abbreviation: UAE, uterine artery embolization.

score were also associated with APH, which may mainly be correlated to the prematurity. These present findings are consistent with those of earlier studies. ${ }^{17,18}$ Given the unpredictable PP with $\mathrm{APH}$, and the associated maternal and neonatal consequences, these present findings support the conclusion, that is, the Society for Maternal Fetal Medicine recommends planned delivery at late preterm for cases without antepartum bleeding or other pregnancy complications. ${ }^{11}$

In view of the ongoing risk of hemorrhage with delayed delivery, identifying women at high risk for APH would be beneficial. Five major determinants were identified for PP with APH, while the following factors as complete PP, anterior placenta and short cervical length were listed in the final regression analysis. These findings were compatible with most of the studies available in present literatures. APH was more prevalent in women with complete placenta previa, when compared to those with incomplete one. ${ }^{19,20}$ Gestational age at bleeding onset was lower in the anterior group than in the posterior group, and the incidence of preterm delivery was higher in the anterior group than in the posterior group. ${ }^{21}$ Even with the use of different cut-off values at the time of examination and frequency of cervical length measurements, short cervix was verified to strongly predict the occurrence of massive $\mathrm{APH}{ }^{22}$

In this study, previous UAE has been identified as a novel eleven-fold increased risk factor for APH. UAE combined with curettage has been proven to be effective and safe for the treatment of cesarean scar pregnancy. Furthermore, UAE also as a salvage measure for intractable post-partum hemorrhage. A few series of small case reports of subsequent pregnancies after UAE also reported no adverse effects, ${ }^{23,24}$ while another study reported a high risk for recurrence of post-partum hemorrhage and abnormal placentation in subsequent pregnancies after UAE. ${ }^{25}$ The possible causes for this new relationship include the abnormal new generation of blood vessels after the previous UAE, in which the more brittle fracture resulted in APH. Another possibility is that some special surgical procedures are always performed after the UAE, leading to surgical trauma of the uterine endometrium or myometrium (prior dilatation and curettage or compression suture).

A partially absent over lying myometrium was found to be a two-fold increased risk factor for APH. The myometrial thinning to less than $1 \mathrm{~mm}$, or the myometrium undetectable on ultrasound, has been used as a prenatal diagnostic sign for abnormally invasive placentas. However, this has only been reported in $50 \%$ of cohort studies. ${ }^{26}$ The myometrium appears excessively thin or undetectable due to the villous invasion, and this can also be observed when the placenta develops underneath a major scar defect, in which the myometrium is thinner than normal, or completely replaced by scar tissue. ${ }^{13}$ Occasionally, the myometrium may partly dehisce or become excessively thin that the placenta can be observed through this at delivery. The absence of the decidua that prevents the separation causes clinically-adherent placenta and subsequent bleeding. ${ }^{27}$ However, it remains uncertain whether the increased risk for APH in women with PP is based on the same mechanism as that in abnormally invasive placentas.

The strength of the present study is the collection for PP patients with a comparatively large sample size during the previous four-year period, and the prenatal routine 
examination, medical strategies, diagnostics and reporting clinicians, and ultrasonic teams remain the same, which ensured the comparability. The major limitation of the study is that this was retrospectively designed in a single medical center. In addition, low-lying placenta previa patients were not included in the present study. Multicentered prospective, controlled studies are needed to obtain more objective conclusions and to establish reliable recommendations in the future.

\section{Conclusion}

In conclusion, obstetricians should be aware of the increased risk of adverse pregnancy outcomes related to APH in women with complete PP, short cervical length, anterior placenta, and partially absent over lying myometrium. Prior UAE is a novel risk factor associated with increased prevalence of APH. These present findings indicate that focusing on the ultrasound assessment and medical history of women at high risk would likely increase the antenatal suspicion of APH, allowing them to be timely admitted for scheduled delivery.

\section{Ethical Approval}

The present study was approved by the Legitimate Review Board of the Army Medical University of China (protocol number 2020-129-01).

\section{Acknowledgments}

We thank AJESCI for its linguistic assistance during the preparation of this manuscript.

\section{Author Contributions}

All authors made substantial contributions to conception and design, acquisition of data, or analysis and interpretation of data; took part in drafting the article or revising it critically for important intellectual content; agreed to submit to the current journal; gave final approval of the version to be published; and agree to be accountable for all aspects of the work.

\section{Funding}

This research was funded by Grants from the Technological Innovation and Application Development Project of Chongqing Science and Technology Bureau (no.cstc2019jscx-msxmX0269).

\section{Disclosure}

The authors report no conflicts of interest for this work.

\section{References}

1. Giordano R, Cacciatore A, Cignini P, Vigna R, Romano $\mathrm{M}$. Antepartum haemorrhage. J Prenat Med. 2010;4(1):12-16.

2. Bhandari S, Raja EA, Shetty A, Bhattacharya S. Maternal and perinatal consequences of antepartum haemorrhage of unknown origin. BJOG. 2014;121(1):44-52. doi:10.1111/1471-0528.12464

3. Bhide A, Thilaganathan B. Recent advances in the management of placenta previa. Curr Opin Obstet Gynecol. 2014;16(6):447-451. doi:10.1097/00001703-200412000-00002

4. Cresswell JA, Ronsmans C, Calvert C, Filippi V. Prevalence of placenta praevia by world region: a systematic review and meta-analysis. Trop Med Int Health. 2013;18(6):712-724. doi: $10.1111 / \mathrm{tmi} .12100$

5. Yang Q, Wen SW, Phillips K, Oppenheimer L, Black D, Walker MC. Comparison of maternal risk factors between placental abruption and placenta previa. Am J Perinatol. 2009;26(4):279-286. doi:10.1055/ s-0028-1103156

6. Rosenberg T, Pariente G, Sergienko R, Wiznitzer A, Sheiner E. Critical analysis of risk factors and outcome of placenta previa. Arch Gynecol Obstet. 2011;284(1):47-51. doi:10.1007/s00404-0101598-7

7. Young JS, White LM. Vaginal bleeding in late pregnancy. Emerg Med Clin North Am. 2019;37(2):251-264. doi:10.1016/j.emc.2019.01.006

8. Crane JM, Van den Hof MC, Dodds L, Armson BA, Liston R. Maternal complications with placenta previa. Am $J$ Perinatol. 2000;17(2):101-105. doi:10.1055/s-2000-9269

9. Vergani P, Ornaghi S, Pozzi I, et al. Placenta previa: distance to internal os and mode of delivery. Am J Obstet Gynecol. 2009;201 (3):266.e1-266. doi:10.1016/j.ajog.2009.06.009

10. Tuzovic L. Complete versus incomplete placenta previa and obstetric outcome. Int J Gynaecol Obstet. 2006;93(2):110-117. doi:10.1016/j. ijgo.2006.02.006

11. Gyamfi-Bannerman C. Society for Maternal-Fetal Medicine (SMFM) consult series \#44: management of bleeding in the late preterm period. Am J Obstet Gynecol. 2018;218(1):B2-B8. doi:10.1016/j. ajog.2017.10.019

12. Jauniaux E, Ayres-de-Campos D, Langhoff-Roos J, Fox KA, Collins S. FIGO placenta accreta diagnosis and management expert consensus panel. FIGO classification for the clinical diagnosis of placenta accreta spectrum disorders. Int $J$ Gynaecol Obstet. 2019;146(1):20-24. doi:10.1002/ijgo.12761

13. Jauniaux E, Collins S, Burton GJ. Placenta accreta spectrum: pathophysiology and evidence-based anatomy for prenatal ultrasound imaging. Am J Obstet Gynecol. 2018;218(1):75-87. doi:10.1016/j. ajog.2017.05.067

14. Jauniaux E, Collins SL, Jurkovic D, Burton GJ. Accreta placentation: a systematic review of prenatal ultrasound imaging and grading of villous invasiveness. Am J Obstet Gynecol. 2016;215(6):712-721. doi:10.1016/j.ajog.2016.07.044

15. Luo L, Sun Q, Ying D, et al. Scoring system for the prediction of the severity of placenta accrete spectrum in women with placenta previa: a prospective observational study. Arch Gynecol Obstet. 2019;300 (3):783-791. doi:10.1007/s00404-019-05217-6

16. Fan D, Wu S, Liu L, et al. Prevalence of antepartum hemorrhage in women with placenta previa: a systematic review and meta-analysis. Sci Rep. 2017;7:40320. doi:10.1038/srep40320

17. Fishman SG, Chasen ST. Risk factors for emergent preterm delivery in women with placenta previa and ultrasound findings suspicious for placenta accreta. J Perinat Med. 2011;39(6):693-696. doi:10.1515/ jpm.2011.086

18. Mastrolia SA, Baumfeld Y, Loverro G, Yohai D, Hershkovitz R, Weintraub AY. Placenta previa associated with severe bleeding leading to hospitalization and delivery: a retrospective population-based cohort study. J Matern Fetal Neonatal Med. 2016;29(21):3467-3471. doi:10.3109/14767058.2015.1131264 
19. Bahar A, Abusham A, Eskandar M, Sobande A, Alsunaidi M. Risk factors and pregnancy outcome in different types of placenta previa. J Obstet Gynaecol Can. 2009;31(2):126-131. doi:10.1016/s17012163(16)34096-8

20. Bhide A, Prefumo F, Moore J, Hollis B, Thilaganathan B. Placental edge to internal os distance in the late third trimester and mode of delivery in placenta praevia. BJOG. 2013;110(9):860-864. doi:10.1111/j.1471-0528.2003.02491.x

21. Sekiguchi A, Nakai A, Kawabata I, Hayashi M, Takeshita T. Type and location of placenta previa affect preterm delivery risk related to antepartum hemorrhage. Int J Med Sci. 2013;10(12):1683-1688. doi:10.7150/ijms.6416

22. Altraigey A, Ellaithy M, Barakat E, Majeed A. Cervical length should be measured for women with placenta previa: cohort study [published online ahead of print]. J Matern Fetal Neonatal Med. 2019;21:1-281. doi:10.1080/14767058.2019.1659239

23. Chauleur C, Fanget C, Tourne G, Levy R, Larchez C, Seffert P. Serious primary post-partum hemorrhage, arterial embolization and future fertility: a retrospective study of 46 cases. Hum Reprod. 2008;23(7):1553-1559. doi:10.1093/humrep/den122
24. Delotte J, Novellas S, Koh C, Bongain A, Chevallier P. Obstetrical prognosis and pregnancy outcome following pelvic arterial embolisation for post-partum hemorrhage. Eur J Obstet Gynecol Reprod Biol. 2009;145(2):129-132. doi:10.1016/j.ejogrb.2009.03.013

25. Poggi SH, Yaeger A, Wahdan Y, Ghidini A. Outcome of pregnancies after pelvic artery embolization for postpartum hemorrhage: retrospective cohort study. Am J Obstet Gynecol. 2015;213(4):576.e1576.e5765. doi:10.1016/j.ajog.2015.06.063

26. Twickler DM, Lucas MJ, Balis AB, et al. Color flow mapping for myometrial invasion in women with a prior cesarean delivery. J Matern Fetal Med. 2000;9(6):330-335. doi:10.1002/1520-6661 (200011/12)9:6<330::AID-MFM1002>3.0.CO;2-O

27. Tantbirojn P, Crum CP, Parast MM. Pathophysiology of placenta creta: the role of decidua and extravillous trophoblast. Placenta. 2008;29(7):639-645. doi:10.1016/j.placenta.2008.04.008

\section{Publish your work in this journal}

Therapeutics and Clinical Risk Management is an international, peerreviewed journal of clinical therapeutics and risk management, focusing on concise rapid reporting of clinical studies in all therapeutic areas, outcomes, safety, and programs for the effective, safe, and sustained use of medicines. This journal is indexed on PubMed Central, CAS,
EMBase, Scopus and the Elsevier Bibliographic databases. The manuscript management system is completely online and includes a very quick and fair peer-review system, which is all easy to use. Visit http://www.dovepress.com/testimonials.php to read real quotes from published authors. 